\title{
Cognitive effects of methylphenidate and levodopa in healthy volunteers
}

Citation for published version (APA):

Linssen, A. M. W., Sambeth, A., Vuurman, E. F. P. M., \& Riedel, W. J. (2014). Cognitive effects of methylphenidate and levodopa in healthy volunteers. European Neuropsychopharmacology, 24(2), 200206. https://doi.org/10.1016/j.euroneuro.2013.09.009

Document status and date:

Published: 01/01/2014

DOI:

10.1016/j.euroneuro.2013.09.009

Document Version:

Publisher's PDF, also known as Version of record

Document license:

Taverne

Please check the document version of this publication:

- A submitted manuscript is the version of the article upon submission and before peer-review. There can be important differences between the submitted version and the official published version of record.

People interested in the research are advised to contact the author for the final version of the publication, or visit the DOI to the publisher's website.

- The final author version and the galley proof are versions of the publication after peer review.

- The final published version features the final layout of the paper including the volume, issue and page numbers.

Link to publication

\footnotetext{
General rights rights.

- You may freely distribute the URL identifying the publication in the public portal. please follow below link for the End User Agreement:

www.umlib.nl/taverne-license

Take down policy

If you believe that this document breaches copyright please contact us at:

repository@maastrichtuniversity.nl

providing details and we will investigate your claim.
}

Copyright and moral rights for the publications made accessible in the public portal are retained by the authors and/or other copyright owners and it is a condition of accessing publications that users recognise and abide by the legal requirements associated with these

- Users may download and print one copy of any publication from the public portal for the purpose of private study or research.

- You may not further distribute the material or use it for any profit-making activity or commercial gain

If the publication is distributed under the terms of Article $25 \mathrm{fa}$ of the Dutch Copyright Act, indicated by the "Taverne" license above, 


\title{
Cognitive effects of methylphenidate and levodopa in healthy volunteers
}

\author{
A.M.W. Linssen*, A. Sambeth, E.F.P.M. Vuurman, W.J. Riedel
}

Department of Neuropsychology and Psychopharmacology, Faculty of Psychology and Neuroscience, Maastricht University, PO Box 616, 6200 MD, Maastricht, The Netherlands

Received 29 January 2013; received in revised form 16 September 2013; accepted 26 September 2013

\author{
KEYWORDS \\ Memory; \\ Event-related \\ potentials; \\ Dopamine; \\ Methylphenidate; \\ Levodopa
}

\begin{abstract}
Our previous study showed enhanced declarative memory consolidation after acute methylphenidate (MPH) administration. The primary aim of the current study was to investigate the duration of this effect. Secondary, the dopaminergic contribution of MPH effects, the electrophysiological correlates of declarative memory, and the specificity of memory enhancing effects of MPH to declarative memory were assessed. Effects of $40 \mathrm{mg}$ of MPH on memory performance were compared to $100 \mathrm{mg}$ of levodopa (LEV) in a placebo-controlled crossover study with 30 healthy volunteers. Memory performance testing included a word learning test, the Sternberg memory scanning task, a paired associates learning task, and a spatial working memory task. During the word learning test, event-related brain potentials (ERPs) were measured. MPH failed to enhance retention of words at a 30 min delay, but it improved $24 \mathrm{~h}$ delayed memory recall relative to PLA and LEV. Furthermore, during encoding, the P3b and P600 ERP latencies were prolonged and the P600 amplitude was larger after LEV compared to PLA and MPH. MPH speeded response times on the Sternberg Memory Scanning task and improved performance on the Paired Associates Learning task, relative to LEV, but not PLA. Performance on the Spatial working memory task was not affected by the treatments. These findings suggest that MPH and LEV might have opposite effects on memory

(c) 2014 Elsevier B.V. and ECNP. All rights reserved.
\end{abstract}

\section{Introduction}

Methylphenidate (MPH) has been shown to not only reduce behavioral symptoms of children with ADHD, but also improve cognitive function in this group (Pietrzak et al., 2006). Some cognition enhancing effects have also been demonstrated in

\footnotetext{
*Corresponding author. Tel.: + 31 433881757; fax: +31433884560 .

E-mail address:

amw.linssen@alumni.maastrichtuniversity.nl (A.M.W. Linssen).
}

healthy volunteers (Repantis et al., 2010; Smith and Farah, 2011). MPH enhances performance in normal controls most notably on tasks measuring speed of processing or working memory (Agay et al., 2010; Elliott et al., 1997; Kollins et al., 1998; Linssen et al., 2011; Mehta et al., 2000). However, a recent study showed that $\mathrm{MPH}$ also improves declarative memory consolidation in healthy individuals (Linssen et al., 2012). It showed enhanced memory recall for words, $30 \mathrm{~min}$ after word list learning if the lists were studied under the influence of MPH. So far, it is still unknown how long this effect lasts. The memory consolidation effect of the pharmacologically similar drug amphetamine has been shown 
to still be present after a $24 \mathrm{~h}$ delay (Zeeuws and Soetens, 2007), indicating a role in late consolidation processes. In the present study, our primary aim was therefore to investigate if the effect of MPH on memory consolidation is also still present a day after word learning.

MPH blocks the reuptake of the catecholamines dopamine and noradrenaline by binding to the transporters, thereby increasing catecholamine availability (Hannestad et al., 2010; Kuczenski and Segal, 1997; Volkow et al., 1998). It is suggested that MPH's potency may be higher for the noradrenaline- than the dopamine transporter (Kuczenski and Segal, 1997), but as dopamine is also transported by the noradrenaline transporter, it is not clear which neurotransmitter system is more affected by MPH (Hannestad et al., 2010; Pacholczyk et al., 1991). Both modulation of noradrenaline- and dopamine alters cognitive function (Chamberlain et al., 2006; Nieoullon, 2002) and hence, MPH's effect on memory consolidation may be mediated through either dopamine, noradrenaline or both. It is difficult to study dopamine and noradrenaline in isolation as catecholaminetransporter blockers, even if specifically blocking only one transporter type, will affect both neurotransmitters and dopamine is a precursor of noradrenaline. However, by comparing MPH to levodopa (LEV), the precursor of dopamine and a predominantly dopaminergic drug, dopaminergic effects could be largely disentangled from noradrenergic effects (Breitenstein et al., 2006).

A secondary aim of the present study was to study the dopaminergic contribution to MPH's effects on memory by comparing effects of LEV to those of MPH on memory in healthy volunteers. Furthermore, we investigated if behavioral results are also reflected by electrophysiological changes in the brain. The present study therefore included electro-encephalography (EEG) measurements, from which event-related potentials (ERPs) were extracted. A previous study showed that a visual word learning task as used in the present study elicits a specific waveform showing several relevant ERP components, including for example P3a and P3b (Linssen et al., 2011). However, because little is known about the effects of dopaminergic manipulation on ERP components measured during a word learning task we chose an exploratory approach. The ERPs were extracted and inspected for the presence of different ERP components, without making specific a priori hypotheses about changes in amplitude and latency of the various components. Finally, to study the specificity of MPH for declarative memory, several other memory tasks, including spatial and verbal (working) memory tasks, were administered.

To address these aims, the effects of a $40 \mathrm{mg}$ dose of MPH on behavioral and electrophysiological measures of a visual word learning task and several other memory tasks were compared to the effect of $100 \mathrm{mg}$ of LEV in a placebo controlled crossover designed study with 30 healthy volunteers. Heart rate, blood pressure and subjective measures were included as control measures.

\section{Experimental procedures}

\subsection{Participants}

Thirty-two healthy volunteers were included, thirty of which completed the study ( 20 male, 10 female, mean age $=20.7, S D=2.3$, range $=18-28$ ). The two participants who dropped out canceled their participation because of other obligations. Participants were recruited by means of local advertisements and were paid to participate. Prescreening occurred using a medical history questionnaire and was followed by medical examination.

The main inclusion criteria were: between 18 and 45 years of age, body mass index between 18 and $30 \mathrm{~kg} / \mathrm{m}^{2}$, normal binocular activity (corrected or uncorrected). The main exclusion criteria were history or presence of mental or physical disorders, consumption of more than 21 alcohol units per week or more than five caffeine-containing drinks per day, pregnancy or lactation, use of medication other than oral contraceptives, use of recreational drugs from 2 weeks before until the end of the experiment.

All subjects gave written informed consent. The study was carried out in accordance with the Declaration of Helsinki (WMO, 2008) and approved by the medical ethical committee of Maastricht University.

\subsection{Design}

The study was conducted according to a double-blind, placebocontrolled, three-way crossover design. Between the testing days, a period of at least $48 \mathrm{~h}$ elapsed, but generally, testing days were scheduled approximately one week apart. Each participant received one of three single treatments including placebo (PLA), $40 \mathrm{mg}$ of MPH and $125 \mathrm{mg}$ of levodopa/carbidopa (LEV) on each testing day (see Supplementary material). LEV was given in combination with $10 \mathrm{mg}$ of domperidone (a peripheral dopamine antagonist) to prevent nausea.

\subsection{Dependent measures}

See Supplementary material.

\subsubsection{Visual verbal learning test}

The visual verbal learning test (VVLT) was used to measure declarative memory (Klaassen et al., 2002). This task is an adapted version of Rey's Auditory Verbal Learning Test (Lezak, 1995) using lists of 30 monosyllabic words in Dutch, validated by Klaassen et al. (2002) and used in multiple published experiments since (e.g. (Linssen et al., 2012; Sambeth et al., 2007; van Ruitenbeek et al., 2008)). The presentation of the same 30 -word list was repeated three times in total using the same sequence of words, each time followed by immediate free verbal recall of all remembered words, which is recorded by the experiment leader. Thirty minutes after immediate free recall of the final series, participants were subjected to a delayed verbal recall test and a forced-choice recognition test. Twenty-four hours later participants were again subjected to a delayed verbal recall and recognition test (using a different set of new words). Three parallel lists were used, using a different list for each of the three testing days. Sequence of the lists was balanced across testing days (see Supplementary material).

During the visual verbal learning task, EEG was recorded using 3 electrodes attached to a cap according to the international 10-20 system (Jasper, 1958) at the $\mathrm{Fz}, \mathrm{Cz}$ and Pz electrode positions (see Supplementary material).

In the ERPs extracted from the electroencephalogram during encoding several peaks could be discerned. P3a and P3b are two subcomponents of the P300, which is interpreted as reflecting brain activity related to updating the mental representation of incoming stimuli (Polich, 2007; Polich and Criado, 2006). P3a is induced by novel or unexpected stimuli, while P3b is associated with context updating and subsequent memory storage (Coull, 1998; Polich, 2007). P600, sometimes referred to as late positive component or positive slow wave has been associated with several higher-level functions, including syntactic processing, item recognition and working 
memory capacity (Chan et al., 2012; Friedman and Johnson, 2000; Lefebvre et al., 2005; Mecklinger 2010; Swaab et al., 2012). We chose to analyze P3a, P3b, and P600 components. since these are associated with memory processing; P300 amplitude during encoding is larger for words subsequently remembered (Friedman and Johnson, 2000; Otten and Donchin, 2000); these components were prominently present in our data; the possible drug effects were mainly visible for these specific components.

\subsubsection{Sternberg memory scanning task}

Sternberg's memory scanning test assesses the speed of scanning items maintained in working memory (Sternberg, 1966). In our test, participants were briefly shown a set of 1,2 or 4 unrelated consonants on a computer screen and asked to memorize them (Linssen et al., 2011). Maintenance in working memory was tested by having participants judge whether presented letters appeared in the memory sequence. For a more detailed prescription of task procedures and dependent measures see (Linssen et al., 2011).

\subsubsection{Paired associates learning}

The visual paired associates learning test requires participants to learn the association between an object and it's location (Owen et al., 2010). Partcipants have to select the box that previously contained the presented item. See Supplementary material for more information.

\subsubsection{Spatial working memory task}

The 'Object relocation' program was used as a spatial working memory task (Kessels et al., 1999; Kessels et al., 2000). In this task, participants were required to relocate ten visual stimuli to their original location. For a more detailed prescription of task procedures and dependent measures see (Linssen et al., 2012).

\subsubsection{Subjective measures}

Participants completed two rating scales of subjective effects, the Profile of Mood States (POMS; (McNair et al., 1992)) and the Bond and Lader (B\&L) visual analog scales (Bond and Lader, 1974). See Supplementary material.

\subsubsection{Physiological measures}

Physiological measures included systolic and diastolic blood pressure and heart rate and were taken at four time points (T0, T50, T130 and T180) on each testing day.

\subsection{Procedure}

On testing days, participants were either collected at their home or came by public transport. They arrived at the lab in fasted condition at either $8.30 \mathrm{am}$ or 9:00 am $(T=0)$. Drug administration occurred according to the schedule presented in Table 1. Participants were given a standardized meal for breakfast. Then, the EEG electrode cap was placed and participants could relax until actual testing started at $T=120$ (see Supplementary material).

Table 1 Drug administration schedule

\begin{tabular}{llll}
\hline Treatment condition & $T=0$ & $T=30$ & $T=60$ \\
\hline Placebo & PLA & PLA & PLA \\
Methylphenidate & MPH & PLA & PLA \\
Levodopa & PLA & dom $^{\text {a }}$ & LEV \\
\hline
\end{tabular}

${ }^{a}$ dom = domperidone.

\subsection{Data analysis}

First, the effect of MPH on declarative memory relative to placebo was analyzed. In order to test whether previous results were replicated, a one-sided paired t-tests between MPH and PLA was conducted.

Next, the LEV results were entered in the analysis. Data were analyzed using a repeated measures analysis of variance (ANOVA), with the within subjects factor treatment (3 levels: PLA, MPH and LEV), running separate analyses for each task. For the EEG data additional within subjects factors were Electrode (3 levels: $\mathrm{Fz}, \mathrm{Cz}$, $\mathrm{Pz}$ ) and Trial ( 3 levels for the three presentations of the word list, only main effects and contrasts related to treatment effects are reported). A priori planned comparisons between each treatment condition (PLA vs. MPH, PLA vs. LEV and MPH vs. LEV) were tested for significance at alpha $<.05$ using LSD correction. These comparisons were made regardless of the outcome of the corresponding overall $F$ test. This is a legitimate procedure if the comparisons are suggested by the theoretical basis of the experiment (Winer, 1971).

Because of the different nature of the subjective and physiological measures, effects on these measures were assessed by paired $t$-tests between either drug vs. PLA on difference scores (relative to morning baseline).

\section{Results}

\subsection{Visual verbal learning test}

\subsubsection{Task performance}

Mean values of dependent measures of the VVLT and $F$ and $p$-values for the ANOVA results including planned contrasts are presented in Table 2.

MPH did not affect immediate or 30 min delayed recall. However, when participants learned the words when under the influence of $\mathrm{MPH}$, they remembered significantly more words at $24 \mathrm{~h}$ delayed recall, compared to PLA $\left(t_{29}=-2.033, p<.05\right.$, one-sided). No other effects of MPH on recognition were noted.

Next, effects of PLA, MPH and LEV were tested in a repeated measures ANOVA with planned comparisons between the two drug conditions and PLA (see Table 2). There was no main effect of treatment in the VVLT. However, planned contrasts showed a near significant difference between PLA and MPH $(p<.051)$ in line with the previously mentioned $t$-test showing better memory recall at the $24 \mathrm{~h}$ delay after $\mathrm{MPH}$. Furthermore, performance on the $24 \mathrm{~h}$ delayed recall was significantly better after MPH compared to LEV $(p=.049)$. Again, performance on the recognition test was not affected by either MPH or LEV.

\subsubsection{ERP measures}

Grand average ERPs, averaged over the three learning trials after PLA, MPH and LEV are shown in Figure 1. A repeated measures ANOVA with treatment, electrode and trial as within subjects factors was run on these data. This analysis showed that there was a main effect of treatment on latency for P3b $\left(F_{1.665,48.278}=4.110, p<.03\right)$, while the main effect of treatment was not significant for any of the other variables $\left(F_{s}<1.980, p_{s}>.155\right)$. Planned contrasts showed that P3b latency was delayed after LEV relative to PLA (PLA: mean $(\mathrm{SEM})=340.8 \mathrm{~ms}$ (3.4); LEV: mean $(\mathrm{SEM})=351.3 \mathrm{~ms}$ (3.5); PLA vs. LEV: $p<.002$ ). P600 amplitude was larger after LEV 
Table 2 Mean scores (SEM) on the Visual verbal learning test

\begin{tabular}{|c|c|c|c|c|c|c|c|}
\hline Mean (SEM) & scores on the VVLT & $F$ & df & $p$ & Contrasts & & \\
\hline PLA & MPH & & & & $\begin{array}{l}\text { PLA vs. } \\
\text { MPH }\end{array}$ & $\begin{array}{l}\text { PLA vs. } \\
\text { LEV }\end{array}$ & $\begin{array}{l}\text { MPH vs. } \\
\text { LEV }\end{array}$ \\
\hline
\end{tabular}

Recall

Immediate recall

Delayed recall $30 \mathrm{~min}$

Delayed recall $24 \mathrm{~h}$
$43.7(2.0) \quad 43.0(2.0)$

$17.0(1.1) \quad 17.2(1.1)$

$13.0(1.2) \quad 14.7(1.2)$

$\begin{array}{llllll}16.6 & (1.1) & .256 & 1.834,51.357 & .756 & .855\end{array}$

$\begin{array}{lllll}13.1 & 1.1 \text { (1) } 3.000 & 1.947,56.463 & .059 & .051\end{array}$

.567

.566

.927

.823

.504

$.049 *$

\section{Recognition}

Reaction time (ms)

$30 \mathrm{~min}$

660

(1.5) 664

(16) 677

(18)

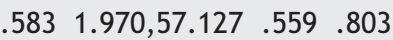

.320

.413

Sensitivity $\left(A^{\prime}\right) 30 \mathrm{~min}$

$2.7(.1)$

$2.7(.1)$

$2.6(.1)$

$\begin{array}{llll}.601 & 1.954,56.677 & .548 & .863\end{array}$

(19) 685

$\begin{array}{lllllllll}\text { (22) } & .716 & 1.900,53.204 & .487 & .94\end{array}$

$2.5(.1) \quad 2.5(.1)$

$2.4(.1)$
$2.5(.1)$

$* p<.05$.

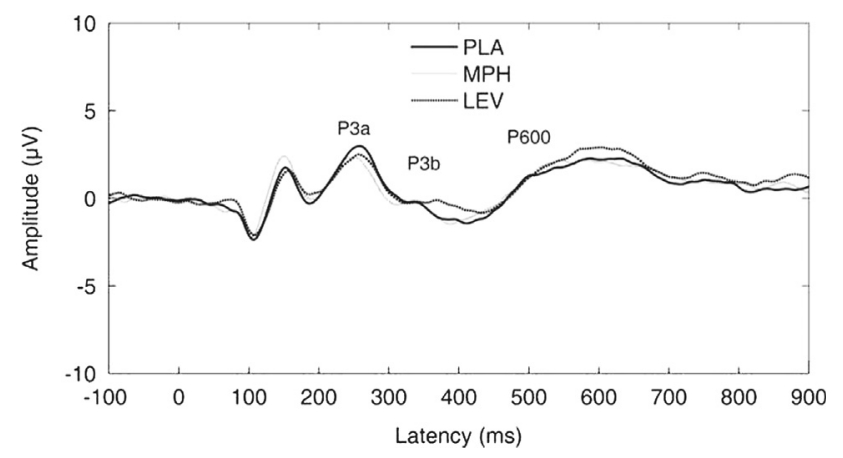

Figure 1 Grand average ERPs showing the P3a, P3b and P600 during the encoding phase (averaged across three learning trials) of the visual verbal learning test. The ERPs depicted were recorded at $\mathrm{Cz}$.

compared to PLA (PLA: mean (SEM) $=4.47 \mu \mathrm{V}$ (.37); LEV: mean $(\mathrm{SEM})=5.09 \mu \mathrm{V}(.31)$; PLA vs. LEV: $p<.018)$.

Figure 2 depicts grand average ERPs measured during recognition testing after PLA, MPH and LEV. The analysis did not reveal significant main effects of treatment $\left(F_{s}<1.229\right.$, $p_{s}>$.297) nor differences between any of the treatments for P3a amplitude (all contrasts, $p>$. 218) and latency (all contrasts, $p>$. 505); P3b amplitude (all contrasts, $p>$. 391) and latency (all contrasts, $p>$. 272); and P600 amplitude (all contrasts, $p>$. 080) and latency (all contrasts, $p>$. 160).

See Supplementary material for an additional analysis only including the EEG of words that were recalled at the $24 \mathrm{~h}$ delayed recall.

\subsection{Other cognitive tasks}

Mean values of dependent measures of the Sternberg memory scanning task, Paired Associates learning and the spatial working memory task and $F$ and $p$-values for the ANOVA results including planned contrasts are presented in Table 3. a

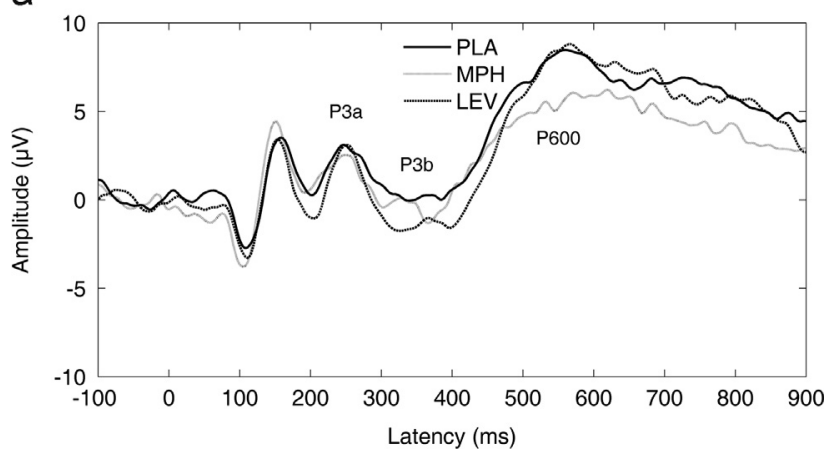

b

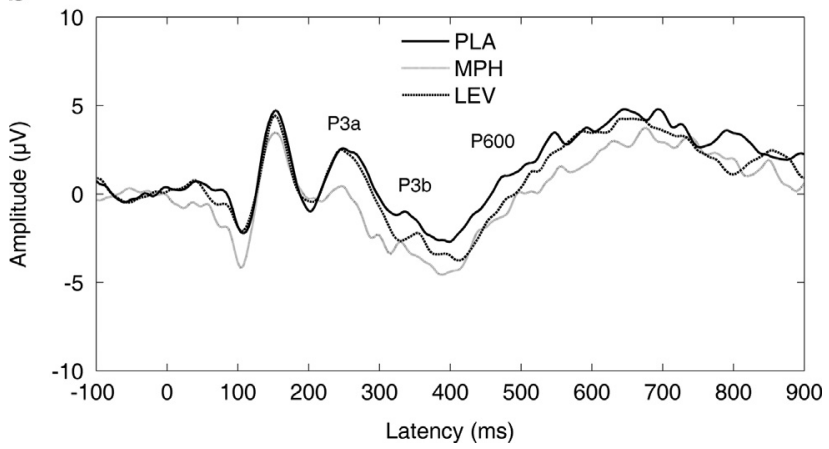

Figure 2 Grand average ERPs showing the P3a, P3b and P600 during the recognition phase of the visual verbal learning test for old (a) and new (b) items. The ERPs depicted were recorded at $\mathrm{Cz}$.

MPH and LEV influences on the Sternberg Memory Scanning task variables did not differ significantly from PLA. However, inspection of the averages again suggested a difference between the two drug conditions. There was a significant main effect of treatment on reaction time. The contrast MPH vs. LEV revealed that responses were significantly faster after MPH relative to LEV (see Table 2). 
Table 3 Mean scores (SEM) on Sternberg Memory Scanning (SMS), Paired Associates Learning (PAL) and Spatial working memory (SWM) tests.

\begin{tabular}{|c|c|c|c|c|c|c|c|c|c|c|c|c|}
\hline \multirow[t]{2}{*}{ SMS } & \multicolumn{6}{|c|}{ Mean (SEM) scores per treatment } & \multirow[t]{2}{*}{$F$} & \multirow[t]{2}{*}{$\mathrm{df}$} & \multirow[t]{2}{*}{$p$} & \multicolumn{3}{|l|}{ Contrasts } \\
\hline & PLA & & $\mathrm{MPH}$ & & LEV & & & & & PLA & PLA & $\mathrm{MPH}$ \\
\hline Slope & 40 & (3) & 37 & (3) & 40 & (3) & 1.178 & $1.988,55.659$ & .315 & .163 & .923 & .224 \\
\hline Intercept & 359 & (8) & 352 & (10) & 361 & (8) & .727 & $1.413,39.570$ & .444 & .450 & .758 & .296 \\
\hline Accuracy & .97 & $(.00)$ & .97 & $(.00)$ & .97 & $(.00)$ & 1.275 & $1.623,47.062$ & .284 & .252 & .488 & .191 \\
\hline $\begin{array}{l}\text { Reaction time (ms) } \\
\text { PAL }\end{array}$ & 471 & $(11)$ & 456 & (11) & 476 & (10) & 3.590 & $1.526,44.263$ & $.047^{*}$ & .097 & .380 & $.029^{*}$ \\
\hline Maximum & 5.7 & $(.1)$ & 6.0 & $(.2)$ & 5.6 & $(.2)$ & 2.518 & $1.769,51.307$ & .097 & .222 & .344 & $.037^{*}$ \\
\hline Mean & 4.0 & $(.1)$ & 4.2 & $(.1)$ & 3.9 & $(.1)$ & 2.970 & $1.742,50.520$ & .067 & .165 & .379 & $.024^{*}$ \\
\hline SWM & & & & & & & & & & & & \\
\hline OTP \% correct & 80.5 & $(2.5)$ & 83.5 & $(2.6)$ & 80.8 & $(2.7)$ & .498 & $1.914,112.913$ & .601 & .359 & .912 & .462 \\
\hline COM \% correct & 80.7 & $(2.2)$ & 78.5 & $(2.6)$ & 80.8 & $(2.4)$ & .392 & $1.891,111.542$ & .665 & .473 & .949 & .469 \\
\hline COM abs err & 154.9 & $(8.4)$ & 166.7 & (13.1) & 156.4 & $(10.6)$ & .525 & $1.612,95.125$ & .555 & .372 & .865 & .487 \\
\hline COM pos fit & 124.6 & $(4.9)$ & 125.0 & $(5.2)$ & 117.2 & $(4.3)$ & 1.282 & $1.795,105.915$ & .280 & .946 & .117 & .156 \\
\hline
\end{tabular}

On the Paired Associates Learning task there was again no difference between either drug condition and PLA, while the two drug conditions did differ significantly from each other. Both max and mean values were higher for MPH compared to LEV.

Performance on the spatial working memory task was not significantly different between the different treatment conditions.

\subsection{Subjective measures}

Analysis of POMS factor scores indicated that after MPH, participants experienced less fatigue at 1 and $3 \mathrm{~h}$ after drug intake $(p<.015$ and $p<.020$ respectively). MPH also caused an increase in reported tension at $1 \mathrm{~h}$ and $2 \mathrm{~h}$ after administration $(p<.041$ and $p<.016$ respectively). Factor scores indicated less vigor at 1 and $3 \mathrm{~h}$ after MPH intake $(p<.004$ and $p<.006$ respectively). The Bond \& Lader factor scores indicated that participants felt more alert $3 \mathrm{~h}$ post MPH intake $(p<.038)$. LEV did not affect subjective feelings as reported by participants.

\subsection{Physiological measures}

Mean values of the physiological measures at morning baseline and respective mean differences from morning baseline are presented in Table 1 in the Supplementary material.

MPH significantly increased heart rate compared to PLA at all time points (T50: $p<.001$; T130: $p<.001$; T180: $p<.001$ ). Furthermore, compared to PLA, MPH also significantly increased systolic blood pressure (T50: $p<.001$; T130: $p<.001$; T180: $p<.001)$ and diastolic blood pressure (T50: $p<.001$; T130: $p<.003$; T180: $p<.003)$. LEV did not affect heart rate and systolic blood pressure at T130, but significantly decreased diastolic blood pressure relative to PLA $(p<.048)$. In both PLA and LEV, heart rate decreased from T0 to T180, but this decrease was significantly smaller after LEV $(p<.036)$. At T180, there were no effects of LEV on blood pressure. Please note that changes in physiological measure reported here are relatively small and all values are still within a normal clinical range for healthy individuals.

\section{Discussion}

In contrast with a previous study (Linssen et al., 2012), MPH failed to enhance retention of words at a 30 min delay in the present study. However, at the $24 \mathrm{~h}$ delay, participants remembered more words during the $24 \mathrm{~h}$ delayed recall when words were learned under the influence of MPH compared to PLA and LEV. The lack of effects on immediate and $30 \mathrm{~min}$ delayed recall suggests that the treatments affected a later phase of consolidation. Furthermore these findings suggest that while MPH had a positive effect on long term retention, LEV had a small negative effect. This is supported by the present findings across several performance and EEG measures (including Sternberg Memory Scanning and Paired Associate Learning tasks) all suggesting opposite effects of MPH and LEV on memory.

In the exploratory analysis of EEG activity during memory encoding the $\mathrm{P} 3 \mathrm{a}, \mathrm{P} 3 \mathrm{~b}$ and P600 ERP components were identified. Latencies of two ERP components, P3b and P600 were delayed after LEV relative to PLA and MPH. As P300 latency is associated with mental speed (Polich, 2012), and P300 and P600 are closely related (Swaab et al., 2012), these effects suggest that LEV slows down memory processing. P600 amplitude was larger after LEV compared to PLA and $\mathrm{MPH}$. Although $\mathrm{P} 600$ is usually related to syntactic processing (Swaab et al., 2012), its similarity to the P300 with respect to sensitivity to stimulus salience, probability and task relevance suggest that an increase in amplitude may reflect increased effort to memorize items.

Performance on the Paired associates learning, Sternberg memory scanning and spatial working memory tasks was not 
different under the influence of MPH relative to PLA. However, $\mathrm{MPH}$ and LEV conditions differed from each other on several measures of the Paired associates learning and Sternberg memory scanning tasks, suggesting that MPH slightly improved working memory while LEV may have had minor deleterious effects on working memory performance.

The LEV dose chosen in this study was rather low and may have failed to enhance dopamine availability. This may explain, why in contrast with previous findings, LEV did not enhance memory performance (Breitenstein et al., 2006; Knecht et al., 2004). Rather, relative to MPH, LEV appeared to have disadvantageous effects on cognitive performance, reflected by general slowing after LEV. This may be explained by a biphasic effect of LEV. A low LEV dose may reduce phasic dopamine release while high doses induce widespread stimulation of postsynaptic receptors, prevailing over presynaptic inhibition (Seeman and Madras, 2002). Consequently, it is possible that LEV decreased dopamine availability relative to $\mathrm{MPH}$, explaining the opposing effects of MPH and LEV.

On the other hand, if the LEV dose was high enough to increase dopamine activity, and it is assumed that healthy volunteers' dopamine levels are optimal, the participants' dopamine level may have risen to a point beyond the optimal level after LEV but not MPH. This may have lead to suboptimal performance, according to the idea that the relationship between dopamine activity and cognitive performance is described by an inverted U curve (Levy, 2009; Schellekens et al., 2009).

Both of these suggestions imply a dopamine mediated effect of both drugs on cognition. On the other hand, it is also possible that the effect of MPH is mediated by noradrenaline or that the combined dopamine and noradrenaline reuptake inhibition is essential in inducing the observed effects, perhaps through noradrenergically mediated effects on attention and/or alertness (Breitenstein et al., 2006; Coull et al., 1997). Indeed, subjects reported to experience less fatigue after MPH and felt more alert after MPH.

The discrepancy between the current and previous findings regarding a potential memory enhancing effect of $M P H$ may be explained by differences in the study procedures. Although timing of task performance relative to dosing was the same in both studies, the hours before administration of the word learning task were spent rather differently. While participants in the previous study had already been subjected to $3.5 \mathrm{~h}$ of cognitive testing, the participants in the present study were well rested before word learning task performance. As MPH is known to reverse the performance disrupting effects of sleep deprivation (Bishop et al., 1997), MPH may have similarly reduced the impact of fatigue, induced by $3.5 \mathrm{~h}$ of computerized (cognitive) testing, in the previous study. Hence, the MPH effect on early consolidation (i.e. within $30 \mathrm{~min}$ ) may depend on the extent to which memory performance may be compromised by fatigue.

In sum, the current study's results suggest MPH and LEV might have opposite effects on memory. Future studies should investigate the mechanism (i.e. relation to dopamine) of these effects.

\section{Role of funding source}

This study was entirely paid for and carried out at Maastricht University.

\section{Contributors}

Anke Linssen, Anke Sambeth, Eric Vuurman and Wim Riedel designed the study and wrote the protocol. Anke Linssen carried out the experiments, performed statistical analyses and wrote the first draft of the manuscript. All authors contributed to and have approved the final manuscript.

\section{Conflict of interest}

Anke Linssen and Anke Sambeth have no financial interests to disclose. Eric FPM Vuurman is employed full time by Maastricht University. He was involved in conducting clinical trials for several pharmaceutical companies over the last three years: MSD, GSK and Transcept pharmaceuticals. Financial compensation for his work was only to Maastricht University and raises no conflict of interest. There were no other commercial or financial relationships that could be construed as a potential conflict of interest. Wim J. Riedel is honorary Professor at Maastricht University. He was an employee of F. Hoffmann-La Roche Ltd, Basel, Switzerland until December 2011 and since then and until present, is an employee of Cambridge Cognition Ltd., Cambridge, United Kingdom. This raises no conflict of interest.

\section{Acknowledgments}

The authors would like to thank the following people for contributing to the study: Dr. Cees van Leeuwen, Lena Lambrecht, Monique Peeters and Rutger Stevelmans.

\section{Appendix A. Supplementary materials}

Supplementary data associated with this article can be found in the online version at http://dx.doi.org/10.1016/ j.euroneuro.2013.09.009.

\section{References}

Agay, N., Yechiam, E., Carmel, Z., Levkovitz, Y., 2010. Non-specific effects of methylphenidate (Ritalin) on cognitive ability and decision-making of ADHD and healthy adults. Psychopharmacology (Berlin) 210, 511-519.

Bishop, C., Roehrs, T., Rosenthal, L., Roth, T., 1997. Alerting effects of methylphenidate under basal and sleep-deprived conditions. Experimental and Clinical Psychopharmacology 5, 344-352.

Bond, A., Lader, M., 1974. The use of analog scales in rating subjective feelings. British Journal of Medical Psychology 47, 211-218.

Breitenstein, C., Floel, A., Korsukewitz, C., Wailke, S., Bushuven, S., Knecht, S., 2006. A shift of paradigm: from noradrenergic to dopaminergic modulation of learning? Journal of the Neurological Sciences 248, 42-47.

Chamberlain, S.R., Muller, U., Blackwell, A.D., Robbins, T.W., Sahakian, B.J., 2006. Noradrenergic modulation of working memory and emotional memory in humans. Psychopharmacology 188, 397-407.

Chan, S.C., Chan, C.C., Kwan, A.S., Ting, K.H., Chui, T.Y., 2012. Orienting attention modulates pain perception: an ERP study. PLoS ONE 7, e40215.

Coull, J.T., 1998. Neural correlates of attention and arousal: insights from electrophysiology, functional neuroimaging and psychopharmacology. Progress in Neurobiology 55, 343-361.

Coull, J.T., Frith, C.D., Dolan, R.J., Frackowiak, R.S., Grasby, P.M., 1997. The neural correlates of the noradrenergic modulation of human attention, arousal and learning. European Journal of Neuroscience 9, 589-598. 
Elliott, R., Sahakian, B.J., Matthews, K., Bannerjea, A., Rimmer, J., Robbins, T.W., 1997. Effects of methylphenidate on spatial working memory and planning in healthy young adults. Psychopharmacology (Berlin) 131, 196-206.

Friedman, D., Johnson Jr., R., 2000. Event-related potential (ERP) studies of memory encoding and retrieval: a selective review. Microscopy Research and Technique 51, 6-28.

Hannestad, J., Gallezot, J.D., Planeta-Wilson, B., Lin, S.F., Williams, W.A., van Dyck, C.H., et al., 2010. Clinically relevant doses of methylphenidate significantly occupy norepinephrine transporters in humans in vivo. Biological Psychiatry 68, 854-860.

Jasper, H.H., 1958. The ten-twenty electrode system of the International Federation. Electroencephalography and Clinical Neurophysiology 10, 370-375.

Kessels, R.P., Postma, A., de Haan, E.H., 1999. Object relocation: a program for setting up, running, and analyzing experiments on memory for object locations. Behavior Research Methods, Instruments, \& Computers 31, 423-428.

Kessels, R.P., Postma, A., Wester, A.J., de Haan, E.H., 2000. Memory for object locations in Korsakoff's amnesia. Cortex 36, 47-57.

Klaassen, T., Riedel, W.J., Deutz, N.E., Van Praag, H.M., 2002. Mood congruent memory bias induced by tryptophan depletion. Psychological Medicine 32, 167-172.

Knecht, S., Breitenstein, C., Bushuven, S., Wailke, S., Kamping, S., Floel, A., et al., 2004. Levodopa: faster and better word learning in normal humans. Annals of Neurology 56, 20-26.

Kollins, S.H., Rush, C.R., Pazzaglia, P.J., Ali, J.A., 1998. Comparison of acute behavioral effects of sustained-release and immediaterelease methylphenidate. Experimental and Clinical Psychopharmacology 6, 367-374.

Kuczenski, R., Segal, D.S., 1997. Effects of methylphenidate on extracellular dopamine, serotonin, and norepinephrine: comparison with amphetamine. Journal of Neurochemistry 68, 2032-2037.

Lefebvre, C.D., Marchand, Y., Eskes, G.A., Connolly, J.F., 2005. Assessment of working memory abilities using an event-related brain potential (ERP)-compatible digit span backward task. Clinical Neurophysiology 116, 1665-1680.

Levy, F., 2009. Dopamine vs noradrenaline: inverted-U effects and ADHD theories. Australian \& New Zealand Journal of Psychiatry 43, 101-108.

Lezak, M.D., 1995. Neuropsychological Assessment, 3rd ed. Oxford University Press, New York.

Linssen, A.M., Riedel, W.J., Sambeth, A., 2011. Effects of tyrosine/ phenylalanine depletion on electrophysiological correlates of memory in healthy volunteers. Journal of Psychopharmacology 25, 230-238.

Linssen, A.M., Vuurman, E.F., Sambeth, A., Nave, S., Spooren, W., Vargas, G., et al., 2011. Contingent negative variation as a dopaminergic biomarker: evidence from dose-related effects of methylphenidate. Psychopharmacology (Berlin) 218, 533-542.

Linssen, A.M., Vuurman, E.F., Sambeth, A., Riedel, W.J., 2012. Methylphenidate produces selective enhancement of declarative memory consolidation in healthy volunteers. Psychopharmacology 221, 611-619.

McNair, D., Lorr, M., Droppleman, L., 1992. EdITS Manual for the Profile of Mood States. Educational and Industrial Testing Service, San Diego.

Mecklinger, A., 2010. The control of long-term memory: brain systems and cognitive processes. Neuroscience and Biobehavioral Reviews 34, 1055-1065.

Mehta, M.A., Owen, A.M., Sahakian, B.J., Mavaddat, N., Pickard, J.D., Robbins, T.W., 2000. Methylphenidate enhances working memory by modulating discrete frontal and parietal lobe regions in the human brain. Journal of Neuroscience 20, RC65.

Nieoullon, A., 2002. Dopamine and the regulation of cognition and attention. Progress in Neurobiology 67, 53-83.
Otten, L.J., Donchin, E., 2000. Relationship between P300 amplitude and subsequent recall for distinctive events: dependence on type of distinctiveness attribute. Psychophysiology 37, 644-661.

Owen, A.M., Hampshire, A., Grahn, J.A., Stenton, R., Dajani, S., Burns, A.S., et al., 2010. Putting brain training to the test. Nature 465, 775-778.

Pacholczyk, T., Blakely, R.D., Amara, S.G., 1991. Expression cloning of a cocaine- and antidepressant-sensitive human noradrenaline transporter. Nature 350, 350-354.

Pietrzak, R.H., Mollica, C.M., Maruff, P., Snyder, P.J., 2006. Cognitive effects of immediate-release methylphenidate in children with attention-deficit/hyperactivity disorder. Neuroscience \& Biobehavioral Reviews 30, 1225-1245.

Polich, J., 2007. Updating P300: an integrative theory of P3a and P3b. Clinical Neurophysiology: Official Journal of the International Federation of Clinical Neurophysiology 118, 2128-2148.

Polich, J., 2012. Neuropsychology of P300. In: Luck, S.J., Kappenman, E.S. (Eds.), The Oxford Handbook of Event-Related Potential Components. Oxford University Press, Oxford.

Polich, J., Criado, J.R., 2006. Neuropsychology and neuropharmacology of P3a and P3b. International Journal of Psychophysiology: Official Journal of the International Organization of Psychophysiology 60, 172-185.

Repantis, D., Schlattmann, P., Laisney, O., Heuser, I., 2010. Modafinil and methylphenidate for neuroenhancement in healthy individuals: a systematic review. Pharmacological Research: The Official Journal of the Italian Pharmacological Society 62, 187-206.

Sambeth, A., Blokland, A., Harmer, C.J., Kilkens, T.O., Nathan, P.J., Porter, R.J., et al., 2007. Sex differences in the effect of acute tryptophan depletion on declarative episodic memory: a pooled analysis of nine studies. Neuroscience and Biobehavioral Reviews 31, 516-529.

Schellekens, A.F., van Oosterwijck, A.W., Ellenbroek, B., de Jong, C.A., Buitelaar, J.K., Cools, L., et al., 2009. The dopamine agonist apomorphine differentially affects cognitive performance in alcohol dependent patients and healthy controls. European Neuropsychopharmacology: The Journal of the European College of Neuropsychopharmacology 19, 68-73.

Seeman, P., Madras, B., 2002. Methylphenidate elevates resting dopamine which lowers the impulse-triggered release of dopamine: a hypothesis. Behavioral Brain Research 130, 79-83.

Smith, M.E., Farah, M.J., 2011. Are prescription stimulants "smart pills"? The epidemiology and cognitive neuroscience of prescription stimulant use by normal healthy individuals. Psychological Bulletin 137, 717-741.

Sternberg, S., 1966. High-speed scanning in human memory. Science 153, 652-654.

Swaab, T.Y., Ledoux, K., Camblin, C.C., Boudewyn, M.A., 2012. Language-related ERP components. In: Luck, S.J., Kappenman, E.S. (Eds.), The Oxford Handbook of Event-Related Potential Components. Oxford University Press, Oxford.

van Ruitenbeek, P., Vermeeren, A., Riedel, W., 2008. Histamine H1receptor blockade in humans affects psychomotor performance but not memory. [Research Support, Non-U.S. Gov't]. Journal of Psychopharmacology 22, 663-672.

Volkow, N.D., Wang, G.J., Fowler, J.S., Gatley, S.J., Logan, J., Ding, Y.S., et al., 1998. Dopamine transporter occupancies in the human brain induced by therapeutic doses of oral methylphenidate. American Journal of Psychiatry 155, 1325-1331.

Winer, J., 1971. Statistical principles in experimental design. McGraw-Hill, New York.

World Medical Association Declaration of Helsinki , 2008.

Zeeuws, I., Soetens, E., 2007. Verbal memory performance improved via an acute administration of D-amphetamine. Human Psychopharmacology 22, 279-287. 